Institute of $\mathbf{F}_{\text {ood and }} \mathbf{A}_{\text {gricultural }} \mathbf{S}_{\text {ciences }}$

\title{
Manual de los Reglamentos del Agua de Florida: Pozos de Agua ${ }^{1}$
}

\author{
Michael T. Olexa, Laura Minton, Dulcy Miller, y Sarah Corbett ${ }^{2}$
}

\section{Agradecimientos}

Los autores agradecen a Richard Budell de la Oficina de Política del Agua Agrícola del Departamento de Agricultura y Servicios al Consumidor de Florida. Los autores también agradecen a David H. Hammonds, Consultor del Programa de Salud Ambiental, Oficina de Programas de Aguas de Drenaje en el Sitio, del Departamento de Salud de Florida, y a Edward A. Bettinger, Consultor del Programa de Salud Ambiental, Oficina de Programas de Agua del Departamento de Salud de Florida.

\section{¿Quien Regula los Pozos de Agua?}

La ley federal no regula directamente la construcción de pozos. Sin embargo, debido a que existe el potencial de contaminación de aguas subterráneas y otros daños ambientales a través de las estructuras de pozo, algunos de los estatutos federales con mas amplia protección ambiental, pueden estar relacionados al respecto. Por ejemplo, la filtración de desechos peligrosos desde un pozo contaminado que contaminó uno de los muchos acuíferos de Florida, podría estar con obligaciones de limpieza bajo el Acta de Responsabilidad, Compensación y Respuesta Ambiental Completa (ARCRAC).

1. Este es el documento EDIS FE081, una publicación del Department of Food and Resource Economics, Florida Cooperative Extension Service, Institute of Food and Agricultural Sciences, University of Florida, Gainesville, FL. Publicada Noviembre 2002. Por favor visite la página electrónica EDIS en http://edis.ifas.ufl.edu.

2. Michael T. Olexa, es profesor del Department of Food and Resource Economics, Florida Cooperative Extension Service, Institute of Food and Agricultural Sciences, University of Florida, Gainesville, FL; y miembro de Florida Bar; Presidente de Agricultural Law Committee of The Florida Bar; y Director del Agricultural Law Center. Laura Minton, Dulcy Miller, y Sarah Corbett son estudiantes graduadas de Levin College of Law, University of Florida, Gainesville, FL. Filiberto Reyes-Villanueva fue el traductor de la versión en ingles al español.

Esta publicación esta diseñada para proporcionar información precisa, actualizada y autorizada sobre esta material. Sin embargo, ya que las leyes, reglas administrativas y decisiones de la corte, sobre las cuales están basados, están sujetas a revisión constante; algunas partes de esta publicación podrían ser obsoletas en cualquier momento. Esta publicación es distribuida bajo el entendimiento que los autores no están involucrados en ninguna representación legal u otros servicios profesionales, y que la información contenida aquí no debe ser considerada como un substituto de una asesoria legal. Esta publicación no esta completa en proporcionar toda la información para lograr el cumplimiento de las leyes y reglamentos que gobiernan la protección del agua. Por estas razones, el uso de estos manuales por cualquier persona constituye un acuerdo para mantener libre de daño a los autores, al Florida Cooperative Extension Service, al Institute of Food and Agricultural Sciences, y a la University of Florida por cualquier demanda por responsabilidad de daños, o gastos en que pueda incurrir cualquier persona, como un resultado de hacer referencia o confianza sobre la información contenida en esta publicación. Esta publicación fue apoyada financieramente por el Florida Department of Agriculture and Consumer Services.

El Instituto de Alimentos y Ciencias Agrícolas es Un empleador que opera bajo Acción Afirmativa y provee Oportunidades Igualitarias, dedicado a promocionar la investigación, a información educativa y otros servicios, únicamente a los individuos e instituciones que operan baj discriminación sin considerar color, raza, sexo, edad, incapacidad u origen. Para más información sobre como obtener otras publicaciones de la extensión, comuníquese con la oficina de Servicio de Extensión de su condado. Servicio de Extensión de la Florida / Instituto de Alimentos y Ciencias Agrícolas / Universidad de la Florida / Christine Taylor Waddill, Decana. 
El Departamento de Protección Ambiental (DPA) ha delegado la mayoría de sus autoridad estatutaria para reglamentar pozos de agua a los individuales Distritos de Manejo de Agua (DMAs), y por lo tanto el apropiado DMA debe ser siempre contactado antes de tomar cualquier acción que involucre pozos de agua. Los estatutos y reglas están diseñados para salvaguardar tanto la calidad del agua extraída de los pozos como la calidad del agua del acuífero. Ambos pueden ser potencialmente contaminados por los pozos involucrados.

\section{¿Cuáles son los Requisitos para la Construcción de un Pozo?}

Un "pozo" se define básicamente como cualquier excavación para remover, localizar o artificialmente recargar agua subterránea. Bajo los estatutos, la construcción, reparación u abandono de pozos debe ser llevado a cabo solamente por contratistas con permiso. Los DMAs aplican pruebas y otros procedimientos para los permisos de los contratistas. Hay, sin embargo, algunas importantes excepciones en los requisitos, como que un contratista con permiso haga el trabajo si el individuo cumple con todas las otras leyes locales y estatales. No se requiere permiso para lo siguiente:

- para propietarios de casas (o inquilino), para construir un pozo de dos pulgadas o menos de diámetro en su propiedad, sólo si es para uso personal o agrícola. El propietario (o inquilino) debe también cumplir con todos los reglamentos y reglas locales y estatales para la construcción del pozo.

- en situaciones donde el DMA determina que el cumplimiento de las reglas resultaría en un gran esfuerzo por la pobreza del solicitante.

Para calificar para la exención del gravamen indebido, debe hacerse una solicitud por escrito al DMA gobernante. Independientemente de cómo se califique la exención, el departamento debe ser notificado de un pozo, una vez que este se haya hecho.

La construcción, reparación o abandono de un pozo, probablemente también requerirá de un permiso de pozo de parte del correspondiente DMA. Las excepciones primarias a esta regla son:

- los permisos para construcción no necesitan ser obtenidos retroactivamente para pozos construidos antes de 1972 (aunque sí se requieren permisos para reparar o abandonar esos pozos).

- cuando uno quiere temporalmente operar equipo para extraer agua.

- cuando el distrito determina que el requisito de un permiso resultaría en un esfuerzo económico por la pobreza para el solicitante.

- un permiso no es requerido antes de la construcción, reparación u abandono de cualquier pozo, eximido por los Estatutos de Florida Secciones 373.303 (7) y 373.326.

Recuerde que los distritos también requieren un permiso para consumir muchas extracciones o desviaciones de agua, independientemente de que sea aplicable la exención del permiso del pozo.

También, el uso imprudente de plaguicidas cerca de los pozos, puede resultar en contaminación del agua subterránea en el respectivo acuífero, causando dispersión de la contaminación. Consecuentemente, el agricultor debe estar familiarizado con todos los reglamentos diseñados para prevenir la contaminación del agua antes de tomar cualquier acción que involucre pozos de agua.

\section{¿Donde Debe estar Ubicado un Pozo?}

Todos los lugares propuestos para un pozo, deben ser pre-aprobados por el distrito correspondiente. Esto protege contra la posibilidad de que un pozo sea inadvertidamente perforado en un área donde existe contaminación del agua subterránea. El DPA proporciona mapas continuamente actualizados de secciones contaminadas de los acuíferos de los DMAs y los correspondientes Departamentos de Salud del Condado. Esta información esta disponible a solicitud de los aplicantes. Los DMAs y los 
departamentos de Salud del Condado también prescriben las distancias mínimas a las áreas contaminadas en donde los pozos pueden ser construidos. El DMA es también responsable por asesorar a los aplicantes respecto a las distancias mínimas para ubicar al pozo respecto a tanques sépticos, campos drenados, áreas para almacenar químicos y otras fuentes potenciales de contaminación.

\section{¿Cuáles son las Especificaciones y los Estádares de Pozo?}

El DPA también publica los requerimientos básicos para las técnicas de perforación y materiales, sedimentación y sellado, identificación y etiquetado en las cabezas de un pozo, y otras áreas altamente especificas. Estos estándares deben ser observados aun donde no es necesario obtener un permiso o licencia. Otra vez, las reglas del DMA suplementan los requerimientos del DPA y deben ser consultadas.

\section{¿Cuáles son los Permisos para un Pozo y las Cuotas?}

Cada DMA establece cuotas para la aplicación de permisos dependiendo primariamente de la naturaleza de la actividad y el tamaño del pozo. Las cuotas pueden ser tan bajas como $\$ 1$ para algunas actividades tales como el abandono, pero no pueden exceder de $\$ 100$ para pozos privados residenciales o $\$ 500$ para pozos de suplemento público. Ninguna cuota será evaluada por cambios de permisos existentes.

Los permisos de construcción son válidos por un período de un año, si la construcción o reparación no pueden ser terminadas dentro de un año, los DMAs tienen dos opciones. El DMA puede extender el plazo o exigir un nuevo permiso. La mayoría de los DMAs exigen un permiso para uso de consumo antes de aprobar un permiso para la construcción de un pozo. Algunos DMAs requieren un permiso de recarga artificial para poner agua dentro del suelo. Algunas de las bases acerca de los permisos para uso de desgaste, las cuales están también reguladas por los distritos individuales, son resumidas en la sección Permisos para Usos de Consumo.

\section{¿Cuáles son los Castigos?}

El DPA, los DMAs y otros cuerpos gubernamentales pueden aplicar tanto castigos civiles como penales contra los violadores de los estatutos o reglas. La construcción, reparación o abandono de pozos sin una licencia, o una violación de los otros requerimientos, es un delito de segundo grado. Cada agencia también esta autorizada para aplicar juicios civiles por daños de hasta $\$ 10,000$ por violación. Los DAMs también tienen autoridad para imponer multas administrativas que no exceden de $\$ 1,000$ por cada violación.

\section{Fuentes}

Estatutos de Florida secciones 373.302-342; Capítulos 62-531 y 62-532, Código Administrativo de Florida; y Titulo 40, Código Administrativo de Florida.

\section{Contactos de Información}

\section{S-1, F-2, L-3 \\ Uso para Consumo \\ ¿Quien Regula el Uso de Consumo?}

La emisión de permisos para uso de consumo es la función exclusiva de los diferentes DMAs, quienes están a cargo del mantenimiento de las reservas de aguas utilizables del estado, a un nivel aceptable. Esto esta en acuerdo con la política del uso de agua de Florida, la cual da preferencia a los usos deseables, y así promueve la preservación de los recursos naturales, los peces y la vida silvestre.

\section{¿Qué Permisos son Requeridos?}

Cuando el uso del agua de un consumidor llega a ciertos niveles umbrales pre-determinados, el DMA exigirá un permiso. Los niveles umbrales son determinados por los DMAs individuales; es importante consultar al respectivo DMA respecto a este umbral. Dos tipos de permisos, individual y general son importantes para el consumo del agua:

1. Los permisos individuales son requeridos cuando la extracción excedió los limites diarios establecidos, los cuales son medidos en galones por día. 
2. Los permisos generales se aplican donde la cantidad de extracción será mínima, según las reglas de los diferentes distritos.

Todos los usos deben ser permitidos a menos que se exenten, incluyendo los usos ya existentes. Esto significa que no hay excepciones especiales para extracciones de aguas subterráneas o superficiales, las cuales existían antes que los requerimientos el permiso de consumo se hicieran efectivos.

Las excepciones generalmente incluyen:

- consumo residencial individual.

- pozos para pruebas o monitoreo.

- pozos privados, superficiales.

- ciertos sistemas de calefacción y enfriado.

- actividades de remoción de aguas necesarias para construcción, si ellas son completadas en menos de seis meses.

La excepción estatutaria, sin embargo, no absuelve a los agricultores quienes están haciendo uso residencial del agua, de cumplir con los deberes legales comunes (ver la sección de Reglamentación Privada para ejemplos). Generalmente, esto significa que el uso del suplemento del agua debe ser razonable. Varios factores pueden ser usados por las cortes para determinar la "razonamiento" del uso, incluyendo:

- el propósito del uso.

- la disponibilidad del cuerpo de agua.

- el valor relativo económico y social.

- el grado del daño del ambiente.

- lo práctico de evitar el daño o lo práctico de ajustar la cantidad de la utilización.

\section{¿Qué Tipo de Agua es Permitida?}

Para la mayor parte, el agua permitida para uso de consumo es el agua subterránea. Sin embargo, la Legislatura ha encontrado recientemente que es seguro, el uso de agua reciclada proporcionada por las plantas de tratamiento de desechos domésticos, es también segura. Así, en un esfuerzo para promover y estimular la conservación del agua, los DMAs ahora permiten el uso del agua reciclable. Para encontrar más acerca de esta nueva fuente para uso de consumo, deberá contactarse al DMA local.

\section{¿Cuál es la Vigencia de los Permisos?}

Los permisos son solamente vigentes por periodos fijos de tiempo. Excepto para las instalaciones públicas, ellos pueden no exceden de 20 años y son usualmente vigentes por periodos mas cortos. Cuando la naturaleza de un uso propuesto es tal que el proceso de la aplicación del permiso puede ser mas largo, el DMA puede emitir un permiso temporal.

La transferencia de permisos entre actividades idénticas por naturaleza en la misma localidad es usualmente permitido, y las condiciones del permiso permanecen iguales. Estos requerimientos son diferentes para los permisos de agua Individual y General.

\section{¿Cuándo es Cancelado un Permiso?}

Cualquier falla para observar continuamente los términos dispuestos por un permiso pueden resultar en su cancelación. Otras razones para cancelación pueden incluir el mal uso del área o instalación permitida o la mitigación no satisfactoria (reducción o aminoramiento) del daño ambiental ocasionado por el uso.

\section{Fuentes}

Estatutos de Florida, Sección 373.203-250;Titulo 40, Código Administrativo de Florida (reglas individuales de DMA)

\section{Contactos de Información}

S-1 